\title{
A Roadmap For Customer Relationship Management
}

Mohammad Dadashzadeh, (E-mail: mdz123@yahoo.com), Wichita State University

Krishnan Krishnaiyer, Wichita State University

Ashok Ramkumar, Wichita State University

Sriram Swaminathan, Wichita State University

\begin{abstract}
Customer Relationship Management (CRM) has become yet another bandwagon in the crowded caravans towards strategic information systems nirvana. In this paper, we contend that beyond serving as a buzzword and a passing fad to acquire an Information Technology (IT) solution from clamoring vendors, management's enthusiasm for CRM can effectively be cultivated to develop the organization's strategic plan for making the customer the focal point of all activities. To that end, we examine CRM technologies by considering what they offer for managing each stage of the Customer Resource Life Cycle (CRLC).
\end{abstract}

\section{Introduction} n the past few years, the technology and practice of CRM has created a whole new market, one that researchers at Aberdeen Group predict could swell to $\$ 24$ billion by 2003. In the annals of corporate life, there are few companies that reach the plateau when they dominate their markets, are continuing to grow fast, and their competitors are struggling to catch up. To names such as Microsoft, Intel, or Oracle, CRM has now added Siebel Systems. Beating by 4 cents the high end of Wall Street analysts' consensus estimate for earnings of 9 cents per share for the last quarter, the company acknowledged 2001 to be a challenging year but that it saw earnings and key revenues growing in 2002. Moreover, dismissing its largest competitors, Oracle and SAP, respectively with 5 and 4 percent share of the overall CRM market, as "non-issue," the company saw profitable opportunities in the reduced competitive threat from some 80 venture-funded CRM companies that disappeared or became irrelevant during the IT spending meltdown of 2001.

What does CRM software actually do to merit all this attention? Simply stated, a number of key things to make intelligent use of customer data in all customer contacts. Aspect Communications (2001) organizes CRM functionalities along the following seven best practices or strategies:

Strategy \#1. Make Self-Service an Attractive Option.

- $\quad$ Use interactive voice response (IVR) systems to deliver customer self-service.

- $\quad$ Combine speech recognition and text-to-speech technology to increase customer acceptance (over older telephone touch pad entry systems).

- $\quad$ Make the service available in different languages.

Readers with comments or questions are encourage to contact the authors via email. 
Strategy \#2. Conduct All Interactions in Real Time.

- $\quad$ Capture, consolidate, and analyze data from all customer contacts.

- $\quad$ Make best use of a contact opportunity.

- $\quad$ Suggest complementary products (cross-sell).

- $\quad$ Suggest a better-quality item to meet the customer profile (up-sell).

- $\quad$ Deliver personalized service.

Strategy \#3. Exploit the Value of Voice over IP.

- $\quad$ Let your Web customers contact a live agent without having to leave the Web environment.

- Make the agents act as a guide to the Web customer, answering questions, making suggestions, closing the sale (sell, up-sale, and cross-sell), and helping make the experience more enjoyable for the customer.

Strategy \#4. Integrate the Web into Your Contacts.

- $\quad$ Provide escorted browsing.

- $\quad$ Support scheduled conferencing and "meet me" capability, where agents and customer meet at a URL.

Strategy \#5. Keep Your Best Agents on Board.

- $\quad$ Use intelligent scheduling to help prevent customer service representative burnout while improving efficiency and increasing customer satisfaction.

- $\quad$ Create optimized agent schedules based on forecast demand and your own business rules and in multi-skill environments.

- $\quad$ Retain agents by empowering them to make changes to their schedules within parameters that you control.

Strategy \#6. Make Extraordinary Service Ordinary.

- $\quad$ Make customers receive the highest level of service that meets their personal need, regardless of how they contact you-by phone, Web, e-mail, fax, or wireless device.

- $\quad$ Use intelligent routing to route customer contacts based on their business value.

- $\quad$ Deliver a consistent, personalized customer experience through all customer interactions.

Strategy \#7. Integrate Everything.

- Integrate all customer contact channels (voice, self-service, Web, wireless) with front- and back-office applications, sales force notebooks, customer service representative desktops, and more.

- $\quad$ Offer all of your services in all channels and make it easy to use more than one channel.

Such state-of-the-art practices in customer analysis and customer service have justifiably provided the fuel to propel CRM as a must-have technology for companies large and small. In their rush to jump on the CRM bandwagon, however, many companies have neglected to formulate a holistic framework for deploying CRM technologies. This has led to CRM implementation failure rates up to 70 percent according to a recent CIO magazine article (Patton, 2001).

In this paper, we examine the CRM space in light of the Customer Resource Life Cycle (CRLC) perspective. We contend that such mapping of CRM technologies to specific functionality areas within an organization's CRLC will significantly improve the chances of success with CRM implementation. 


\section{The Customer Resource Life Cycle}

CRM encompasses a wide range of technologies that cover all functional areas within the firm. Any attempt at listing the features and functionalities within the CRM space quickly becomes a daunting task. It is much easier to step back and identify strategic opportunities for enhancing the added value, or reducing costs in creating value, in every interaction the firm goes through with its customers. These strategic opportunities can then be mapped unto CRM technologies for adoption consideration.

The Customer Resource Life Cycle (Ives and Learmonth, 1984) provides an organized approach for examining the various phases a customer goes through in acquiring a product, or service, from a firm. There are four main phases in the CRLC. In the requirements phase, the need for a product, or service, is established and desired attributes are determined. During the acquisition phase, the customer selects a vendor, places an order and pays for it, acquires goods or services and tests them for acceptance. Ownership brings with it interaction opportunities for training, maintenance, repair, and upgrade. The final phase, retirement, begins when the customer contemplates buying again, trading in the old product, and so on.

Breaking the four main phases further allows us to consider more closely how the various stages are being supported at present and how support could be improved in the future. The CRLC is divided into 13 stages depicted in the following table:

\begin{tabular}{|l|l|}
\hline \multicolumn{1}{|c|}{ Stage } & \multicolumn{1}{c|}{ Example Opportunities } \\
\hline Establish Need & $\begin{array}{l}\text { Creating an incentive for a product when a related purchase is made. } \\
\text { Informing that a part needs replacement prior to its failure. }\end{array}$ \\
\hline Specify Requirements & Providing expert assistance with product selection and configuration. \\
\hline Select Source & $\begin{array}{l}\text { Being represented where customers do comparison shopping. } \\
\text { Offering competitive comparisons. } \\
\text { Providing ease of access to the source. }\end{array}$ \\
\hline Place Order & $\begin{array}{l}\text { Minimizing transaction cost for returning customers. } \\
\text { Providing escorted guidance while ordering. } \\
\text { Supporting multiple contact channels for ordering (EDI, voice, fax, e-mail, } \\
\text { Web, wireless). }\end{array}$ \\
\hline Authorize Payment & $\begin{array}{l}\text { Extending credit. } \\
\text { Supporting various on-line payment mechanisms. } \\
\text { Forgoing payment for permission to sell other products. }\end{array}$ \\
\hline Acquire & $\begin{array}{l}\text { Tracking the delivery of product. } \\
\text { Supporting digital delivery of product and/or product companions. }\end{array}$ \\
\hline Test and Accept & $\begin{array}{l}\text { Offering try out prior to purchase. } \\
\text { Automating installation, testing, and registration. }\end{array}$ \\
\hline Integrate & Providing integrated information on assets acquired. \\
\hline Monitor Use & Building an information base into products recording usage. \\
\hline Upgrade & Linking usage to live update/upgrade. \\
\hline Maintain & $\begin{array}{l}\text { Providing an intelligent, self-service preventive maintenance log. } \\
\text { Integrating expert diagnosis and troubleshooting into products. }\end{array}$ \\
\hline Transfer or Dispose & $\begin{array}{l}\text { Supporting needed disposal. } \\
\text { Creating competitive trade-in upgrade opportunities. }\end{array}$ \\
\hline Account For & Providing total cost of ownership information. \\
\hline
\end{tabular}

It is important to recognize that some stages in the CRLC may be absent or combined in a particular business. Furthermore, it is the dynamics of the organization as well as the nature of the product that determine which phase can benefit the most from investments in CRM technologies. For example, although it is generally true that before an innovative product can be sold one needs to educate potential customers, the burden for establishing need is greater for a new company than it is for one with an established base of customers who can be enticed into transferring to the innovative product. 


\section{CRM and the CRLC}

Having considered the all-encompassing nature of the CRLC in relation to the interactions of a customer and the firm, there should be no surprise that the functions and features offered by CRM technologies must address one or more of the CRLC stages. Every firm endeavors to acquire "profitable" customers. Every customer begins life as a prospect that the firm must convert into a customer. Sales force automation software, such as Siebel Systems' Sales Enterprise application, is an important tool that supports the efforts for acquiring customers.

Sales force automation software must not only capture "new" customer data for both CRM and ERP (Enterprise Resource Planning) systems, it must also manage data about "existing" customers who play the role of a prospect many times in the course of their relationship with the firm. Often, a salesperson is the last to know that a customer is in prospect mode. Indeed, customer service and support representatives are, quite often, the first to learn that a customer is looking for, or needs, something new or improved. The integration between help desk software, call center software, service center software, and the sales force automation system is a necessary ingredient for recording customer leads and channeling them to sales force, along a workflow termed the sales pipeline, for rapid follow-up from "cradle to close." (McKie, 2001)

A direct sales force is, of course, the prominent remnant of the past when businesses acquired customers by actively selling to them using a sales force, direct marketing, advertising, and events. New techniques are needed today to manage the new breed of $e$-customers acquired through Web storefronts.

Multi-channel $e$-customer interaction management software ensures that $e$-customers can communicate with customer service representatives from the Web storefront via chat, instant messaging, e-mail, fax, as well as voice. Click stream analysis software captures clicks and keystrokes from the customer's session to provide data for subsequent analysis to understand $e$-customer behavior and buying patterns.

For most companies, the bulk of customer relationship management occurs with the efforts for retaining customers. Help desk, call center, and service center software from vendors such as Remedy are the CRM applications that not only support diverse transactions such as getting help with a product, resolving billing questions, or fulfilling warranty claims, but also capture a great deal of data to be mined.

Portal software such as Aspect Portal gives suppliers the chance to have a multi-channel contact center that synchronizes all customer interactions through a single gateway. The principal advantage of the portal approach is to integrate all channels into a consistent CRM strategy. In other words, to make the customer experience uniform for that customer no matter how contact is initiated.

In the same way that portal integration is necessary to streamline the entire customer contact management operation, the ERP-CRM integration is vital for providing a holistic picture of customer activity within a business. As pointed out by McKie (2001), shouldn't customers know if their orders are delayed or moved to back-order status? Information such as this that is captured in real-time in the ERP system can be moved in real-time to the CRM systems. And, if customers are to be treated as genuine business partners, such pertinent ERP data should be accessible to them via Web-based, self-service portals. It can be effectively argued that high-value customers must be able to see anything important about their business relationship with their supplier as openly as the supplier's internal staff.

Retaining customers also requires proactive measures. Loyalty programs, such as frequent flyer and grocery discount cards, are examples of customer retention tools that also contribute additional data to the storehouse of customer data to be mined. For the $e$-customer, CRM software tracks loyalty bonuses gained by frequent shoppers, in the form of Web currencies such as "beenz" (virtual credit redeemable at other participating sites) or "ClickMiles" (frequent flyer miles). Another retention strategy supported by CRM technologies is to create customer communities about the product or service. 
Customer relationship management, at its core, means enhancing the relationship with customers by providing added value. To add value, a better understanding of each customer is needed. CRM data mining solutions can help discover patterns and form customer profiles that can proactively be used to create value and enhance the existing relationships. Customer enhancement has the potential for contributing the most toward the bottom line of an organization (Reddy, 2001).

\section{A CRM Strategy}

As we have seen, CRM technologies span a broad range of functionalities that can support the various stages of the Customer Resource Life Cycle (CRLC). These features include: sales force automation, pipeline management, call centers, telemarketing, product configuration, dealer and distribution management, field service management, customer contact management, campaign management, customer analysis, self service, personalization, and supply chain management. The CRM space, of course, remains far from reaching a stable state. ERP vendors are hard at work to integrate CRM functionalities into their products. Nevertheless, there may always be justification for a "best-of-breed" approach to CRM-ERP integration. And, with application service providers adding CRM modules as just another class of application to be offered on a monthly rental fee, there are strong reasons for every business to have a CRM system tomorrow, in the same way that they have an accounting system today (McKie, 2001).

The strongest reason to invest in CRM is, undoubtedly, to actively leverage the customer asset. As pointed out by McKie (2001), increased competition and decreased profitability tend to act as the wake-up call for business managers to start thinking about managing customer assets. Customers are every business' most valuable (and free) advisors. CRM data mining and customer feedback management tools help to make sure those businesses properly collect and act upon their advice.

In developing a CRM deployment strategy, the starting point should not be looking at specific technologies. Instead, an organization's CRM strategy should be formulated in terms of smart (specific, measurable, attainable, realistic, and time-limited) improvement objectives in one or more stages of the CRLC. Reddy (2001) offers the following examples:

- Increase new customer acquisition through Web-based channels by x percent over the next three quarters.

- $\quad$ Achieve cross- and up-selling targets of $\$ \mathrm{x}$ over the next two quarters from customer service and technical support areas.

Once smart CRM objectives are formulated, the process of mapping CRM technologies for their realization becomes less susceptible to the implementation failure rate haunting IT "silver bullets."

\section{References}

1. Aspect Communications. Seven Powerful Strategies for Increases CRM Profitability. San Jose, CA: Aspect Communications. 2001.

2. Ives, B. and Learmonth, G.P. "The Information Systems as a Competitive Weapon," Communications of the ACM, 27:12, pp. 1193-1201, 1984.

3. McKie, S. “CRM: Customer Role Management," Intelligent CRM, 1:1, 2001.

4. $\quad$ Patton, S. "The Truth About CRM," CIO Magazine, May 1, 2001.

5. Reddy, R. "Through a Lens Smartly," Intelligent CRM, March 27, 2001. 
Notes 